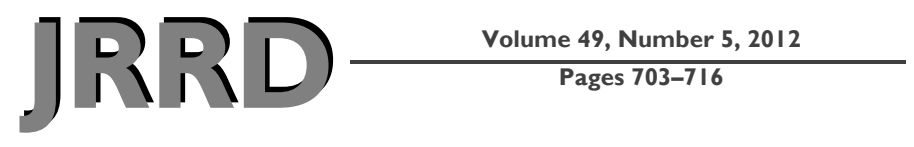

\title{
Pharmacotherapy for posttraumatic stress disorder: Review with clinical applications
}

\author{
Matthew Jeffreys, MD; ${ }^{*}$ Bruce Capehart, MD, MBA; ${ }^{2}$ Matthew J. Friedman, MD, $\mathbf{P h D}^{\mathbf{3}}$ \\ ${ }^{1}$ South Texas Veterans Health Care System, San Antonio, TX; and University of Texas Health Science Center, San Anto- \\ nio, TX; ${ }^{2}$ Durham Department of Veterans Affairs Medical Center (VAMC), Durham, NC; and Duke University, \\ Durham, NC; ${ }^{3}$ National Center for PTSD, White River Junction, VT; White River Junction VAMC, White River Junc- \\ tion, VT; and Dartmouth Medical School, Hanover, $\mathrm{NH}$
}

\begin{abstract}
Posttraumatic stress disorder (PTSD) is a prevalent psychiatric diagnosis among veterans and has high comorbidity with other medical and psychiatric conditions. This article reviews the pharmacotherapy recommendations from the 2010 revised Department of Veterans Affairs/Department of Defense Clinical Practice Guideline (CPG) for PTSD and provides practical PTSD treatment recommendations for clinicians. While evidence-based, trauma-focused psychotherapy is the preferred treatment for PTSD, pharmacotherapy is also an important treatment option. First-line pharmacotherapy agents include selective serotonin reuptake inhibitors and the selective serotonin-norepinephrine reuptake inhibitor venlafaxine. Second-line agents have less evidence for their usefulness in PTSD and carry a potentially greater side effect burden. They include nefazodone, mirtazapine, tricyclic antidepressants, and monoamine oxidase inhibitors. Prazosin is beneficial for nightmares. Benzodiazepines and antipsychotics, either as monotherapy or used adjunctively, are not recommended in the treatment of PTSD. Treating co-occurring disorders, such as major depressive disorder, substance use disorders, and traumatic brain injury, is essential in maximizing treatment outcomes in PTSD. The CPG provides evidence-based treatment recommendations for treating PTSD with and without such cooccurring disorders.
\end{abstract}

Key words: best practices, guidelines, health services, medications, mental health, patient care, pharmacotherapy, PTSD, treatment, veterans.

\section{INTRODUCTION}

The prevalence of posttraumatic stress disorder (PTSD) has been estimated to be 7.8 percent in the general population [1]. A higher PTSD prevalence has been estimated in veterans. The prevalence of PTSD in Vietnam veterans is estimated to be 18.7 percent lifetime warrelated and 9.1 percent current war-related. A prevalence of PTSD between 15 and 17 percent has been estimated in Iraq and Afghanistan veterans (Operation Iraqi Freedom/

\footnotetext{
Abbreviations: $\mathrm{BP}=$ bipolar disorder, CAPS = ClinicianAdministered Posttraumatic Stress Disorder Scale, CPG = Clinical Practice Guideline, DOD = Department of Defense, HPA = hypothalamic-pituitary-adrenal, MAOI = monoamine oxidase inhibitor, $\mathrm{MDD}=$ major depressive disorder, OIF/OEF/OND = Operation Iraqi Freedom/Operation Enduring Freedom/ Operation New Dawn, PCL = Posttraumatic Stress Disorder Symptom Checklist, PE = prolonged exposure, PTSD = posttraumatic stress disorder, RCT = randomized controlled trial, SNRI = serotonin-norepinephrine reuptake inhibitor, SSRI = selective serotonin reuptake inhibitor, SUD = substance use disorder, TBI = traumatic brain injury, TCA = tricyclic antidepressant, VA = Department of Veterans Affairs.

*Address all correspondence to Matthew Jeffreys, MD; South Texas Veterans Health Care System-Psychiatry, 5788 Eckhert Rd, San Antonio, TX 78240; 210-699-2145; fax: 210-699-2176. Email: Matthew.Jeffreys@va.gov http://dx.doi.org/10.1682/JRRD.2011.09.0183
} 
Operation Enduring Freedom/Operation New Dawn [OIF/ OEF/OND]). The prevalence varies depending on the methods used and the time at which PTSD is assessed [2$3]$. Although these rates are greater than the prevalence of PTSD in the general population, the prevalence of PTSD may be even higher in outpatient general medical settings, perhaps because PTSD is associated with comorbid medical problems and patients with PTSD are high utilizers of healthcare. Estimates of PTSD for veterans in medical settings have varied from 11.2 percent using stricter diagnostic criteria to as high as 20-30 percent using more liberal diagnostic criteria [3-9]. Experiencing combat wounds is recognized to further increase the risk of PTSD twofold [10]. Many of these patients will be seen initially by medical professionals in either primary care or general mental health settings, creating a need for physicians in all specialties to become familiar with the initial management steps, assessment, and diagnosis of PTSD.

Questions and concerns have arisen about the current prescribing practices for PTSD among OIF/OEF/OND veterans as well as veterans from prior eras. We draw special attention to benzodiazepines and atypical antipsychotics, because these two classes of medication are prescribed for PTSD despite little evidence for their efficacy and considerable concern about their potential harm. Benzodiazepine prescribing within the Department of Veterans Affairs (VA) for veterans with PTSD has raised concerns about benzodiazepines' abuse potential given that studies have not found them effective in preventing or treating PTSD [11-14]. Further, because benzodiazepines reduce anxiety without addressing the underlying PTSD, clinicians may incorrectly believe the patient has improved, thus delaying definitive PTSD care.

Atypical antipsychotics also are believed to be overprescribed for PTSD, causing both excessive medication costs and a risk of harmful side effects, including obesity and metabolic syndrome. An estimated 34 percent of veterans with PTSD on medications receive atypical antipsychotics, and 77 percent of these veterans do not have a comorbid diagnosis of schizophrenia or bipolar disorder (BP) [15-16]. The 2010 VA/Department of Defense (DOD) VA/DOD Clinical Practice Guideline for Management of Post-Traumatic Stress ${ }^{*}$ recommends against atypi-

\footnotetext{
* The VA/DOD CPG for Management of Post-Traumatic Stress can be downloaded at no charge from www.healthquality.va.gov/ptsd/ ptsd full.pdf.
}

cal antipsychotic use as monotherapy for PTSD [17]. Furthermore, a recent large, multisite VA Cooperative Study concerning adjunctive use of risperidone demonstrated it to be no more effective than placebo at lowering PTSD symptoms after 24 weeks of treatment [18]. As a result, the clinical practice guideline (CPG) is being updated to recommend against prescribing risperidone as an adjunctive agent, concluding that evidence is insufficient to recommend any other atypical antipsychotic as adjunctive treatment for PTSD. We will review this evidence subsequently.

While OIF/OEF/OND veterans access mental health services at a greater rate than combat veterans from prior conflicts, most patients with PTSD will be seen and possibly treated in primary care, medical specialty, or general mental health settings [19]. Physicians and midlevel practitioners in these settings should be familiar with the recommended pharmacologic management of PTSD and the appropriate indications for referral to specialty mental health care. Prescribers should remain aware that appropriate PTSD care involves not only providing the best initial evidence-based pharmacotherapy, but also ideally delivering it collaboratively with a psychotherapist who is trained in evidence-based, trauma-focused psychotherapy.

The recommended first-line pharmacotherapy for PTSD includes selective serotonin reuptake inhibitors (SSRIs) or the serotonin-norepinephrine reuptake inhibitor (SNRI) venlafaxine. Prazosin is recommended for nightmares not relieved by first-line treatments. To identify patients with trauma-related distress who may require further evaluation and treatment, we have found the PTSD Symptom Checklist (PCL) ${ }^{\dagger}$ to be a useful selfreport scale that can help monitor PTSD symptoms over time [20].

This review is based primarily on the recently revised CPG, which provides excellent guidance regarding initial pharmacotherapy and psychotherapy interventions for PTSD. Treatment options including both pharmacotherapy and psychotherapy need to be discussed with patients experiencing PTSD or trauma-related distress. The CPG will help VA medical providers in their clinical settings identify veterans who have experienced trauma and initiate pharmacotherapy and/or psychotherapy when indicated in the context of a collaborative therapeutic relationship. First- and second-line pharmacotherapy

\footnotetext{
${ }^{\dagger}$ Instructions and forms for the PCL can be found at www.ptsd.va.gov.
} 
options, as well as medications to avoid, will be discussed. Patients with continuing distress will need referral for PTSD specialty consultation and further therapeutic intervention to improve functioning and maximize their treatment success.

\section{METHODS}

Electronic databases such as PubMed and Ovid were searched for randomized controlled trials (RCTs) of PTSD pharmacotherapy for the period between January 2002 and August 2009. Articles meeting these criteria were reviewed and rated based on the strength of the supporting evidence to update the CPG. Further details of the review and rating process are outlined in the CPG [17]. Two of the authors (Dr. Jeffreys and Dr. Friedman) served as members of the CPG Pharmacotherapy Working Group. In addition to drawing on the CPG, we searched PubMed for pertinent studies published after August 2009 and drew on our own clinical experiences to provide the clinical applications.

\section{RESULTS OF REVIEW WITH CLINICAL APPLICATIONS}

\section{Posttraumatic Stress Disorder Patients in Medical Settings}

The hallmark of PTSD is a psychological response to a traumatic event that poses a threat of death or injury to the patient or another individual [21]. Patients who experience physical injury during their psychological trauma are at greater risk of developing PTSD, particularly because their injury (especially a permanent injury) serves as a powerful reminder of the traumatic experience. It is not surprising, then, that patients who experience physical injury have varying levels of traumarelated distress ranging from a few symptoms to the full diagnostic picture of PTSD. While most traumatized individuals do not develop PTSD, the incidence of PTSD varies and is influenced by a complex interaction of individual factors such as genetic predisposition and sex, with mediating factors such as social support, trauma severity, peritraumatic dissociation, and trauma frequency [22-25]. The clinical outcome after trauma will be determined by this complex interplay between the individual's history, genetic predisposition, social envi- ronment, physical and psychological response to the trauma, and social support network. Patients with injuries or life-threatening illnesses are at risk for significant trauma-related distress during episodes of care for their medical illnesses and injuries.

Symptoms of trauma-related distress can interfere with participation in medical care through PTSD symptoms such as decreased participation in activities, estrangement from others, sleep disturbance, irritability, poor concentration, and memory problems. Medication adherence can be decreased by problems with concentration and the resulting change in memory. A sense of futility or hopelessness can further diminish the patient's willingness to participate in medical care. Detecting PTSD and trauma-related distress in the medical environment can be difficult to differentiate from traumatic brain injury (TBI) or symptoms due to other psychiatric disorders such as depression [26-27]. PTSD and depression have many symptoms in common, such as sleep disturbance, decreased participation in activities, estrangement from others, and decreased concentration. Mild TBI and PTSD also share common symptoms, such as decreased concentration, sleep disturbances, irritability, and increased arousal. When a clinician is evaluating or treating a combat veteran with physical problems and suspected PTSD, consultation with a specialty mental health clinician can help resolve these difficult diagnostic questions.

Establishing rapport and helping patients make the connection between their current emotional and physical distress and trauma symptoms are very important in providing the basis for initiating pharmacotherapy. Veterans with combat injuries or even overuse injuries of the musculoskeletal system from combat activities may report increased physical pain in association with untreated anxiety symptoms. Offering the patient an explanation for untreated emotional pain as an aggravating - but not causative-factor for physical pain may be a useful step in building a therapeutic relationship. This relationship plays a crucial role in establishing the necessary trust to begin addressing the societal, system, and internal barriers between recognizing PTSD and seeking effective treatment. Listening empathically, demonstrating clinical competence, discussing the courage to seek treatment, and offering any other indicated clinical interventions to establish rapport will help decrease the potential stigma from seeking mental health care and assist patients' movement from precontemplation to action in their treatment [28-29]. 
Establishing a baseline measurement of symptom severity with a well-validated instrument before initiating treatment is useful so that clinical progress can be monitored. We recommend the PCL for this purpose [20]. The PCL is a widely available 17-item self-report scale helpful in identifying symptoms associated with trauma-related distress and PTSD. It is not a substitute for a thorough diagnostic evaluation for PTSD through a structured clinical interview such as the Clinician-Administered PTSD Scale (CAPS) [30]. The PCL can be a useful guide in raising clinical awareness and quantifying PTSD symptom severity. Use of this instrument can also help patients understand which PTSD symptoms are causing subjective distress and functional impairment. Such clarification often overcomes barriers to treatment and helps patients move toward specialty mental health referral when indicated. In general, PCL scores of 50 and above have the greatest sensitivity and specificity for trauma-related distress, ${ }^{*}$ but these cutoff scores vary in different settings because of overlap of symptoms such as depression in the medical setting or TBI in the rehabilitation medicine setting [31-33].

\section{Initiating Effective Pharmacotherapy}

PTSD and other anxiety disorders demonstrate a dysregulation in the fear circuitry that is important in the normal "fight or flight" response. A number of physiological differences are reported in persons with PTSD, including disturbances in neurological integration of the fear circuitry [34], reduced serotoninergic modulation of the fear response in key areas such as the amygdala [35], and dysregulation of the hypothalamic-pituitary-adrenal (HPA) axis. Abnormal HPA axis function is often expressed by lower baseline cortisol levels and excessive suppression of the HPA axis by exogenous steroids [36-38]. Studies on blood pressure and other measures of sympathetic nervous system arousal at rest in patients with PTSD have been inconsistent but show increased resting heart rate and muscle tension. Studies are more consistent in showing physiological hyperreactivity following exposure to a reminder of the traumatic event [39].

The CPG provides a useful reference for practitioners initiating pharmacotherapy in patients with PTSD. The CPG developers considered only RCTs in the published literature for the CPG's treatment recommendations.

\footnotetext{
* Further instructions and forms for the CAPS and PCL are available at www.ptsd.va.gov.
}

Studies were rated on their strength and quality of evidence. A summary of first-line and second-line pharmacotherapy agents for treating PTSD is shown in the Table.

First-line agents recommended by the CPG include the SSRIs and the SNRI venlafaxine. These medications reduce the three core symptom clusters of PTSD: reexperiencing, hyperarousal, and avoidance. Currently, only the SSRIs sertraline and paroxetine are approved by the Food and Drug Administration for treatment of PTSD. All other medications for PTSD are considered off-label use. RCTs have provided strong evidence for the effectiveness of sertraline, paroxetine, and venlafaxine in the treatment of PTSD [40-43]. These agents, along with others affecting the serotonin system, are hypothesized to be effective because of their effect on the altered serotonergic receptors in the amygdala and other parts of the fear circuitry. Fluoxetine was found to be superior to placebo in treating and preventing relapse of PTSD symptoms [44-45]. Some other SSRIs, such as citalopram and fluvoxamine, currently have far less evidence for their effectiveness in PTSD [46-47]. Veterans with chronic treatment refractory PTSD seem to be especially difficult to treat with SSRIs [48]. This emphasizes the need for a comprehensive treatment approach that includes the trauma-focused psychotherapies. The main adverse side effect of SSRI and SNRI medications is sexual dysfunction, most commonly delayed orgasm. Many persons starting on an SSRI or SNRI also report mild increases in gastrointestinal motility that resolve within 1-2 weeks.

Prazosin has proved to be an effective treatment for PTSD-related nightmares [49-50]. While the specific mechanism by which prazosin decreases nightmares is unknown, it is hypothesized that by blocking the alpha-1 receptor in the central nervous system, prazosin decreases nightmares that result from increased adrenergic responsiveness in PTSD. It blocks the effects of norepinephrine release from noradrenergic neurons, such as those originating within the locus ceruleus of the brainstem. Despite prazosin's established usefulness for reducing nightmares, results have been mixed regarding its efficacy for the full PTSD syndrome [51]. Hypotension is the main side effect to monitor when initiating prazosin. Although this has not proven to be a problem for most patients receiving this medication, a slow titration is recommended for patients without comorbid hypertension.

Second-line recommended agents include medications with some limitations. These choices include the older 
Table.

Recommended first-line and second-line pharmacotherapy agents for treating posttraumatic stress disorder (PTSD). Adapted from Department of Veterans Affairs/Department of Defense Clinical Practice Guideline for Management of Post-Traumatic Stress.

\begin{tabular}{|c|c|c|c|c|}
\hline $\begin{array}{c}\text { Strength of } \\
\text { Recommendation }\end{array}$ & Substantial Benefit & Some Benefit & Unknown Benefit & No Benefit or Harm \\
\hline $\mathrm{A}$ & SSRIs, SNRIs & - & - & - \\
\hline B & - & $\begin{array}{l}\text { Mirtazapine, TCAs, } \\
\text { MAOIs (phenelzine), } \\
\text { prazosin (night- } \\
\text { mares), nefazodone } \\
\text { (caution) }\end{array}$ & - & - \\
\hline $\mathrm{C}$ & - & - & Prazosin (PTSD) & - \\
\hline $\mathrm{D}$ & - & - & - & $\begin{array}{l}\text { Guanfacine, topiramate, } \\
\text { valproate, tiagabine, ben- } \\
\text { zodiazepines (harm), ris- } \\
\text { peridone (adjunct) }\end{array}$ \\
\hline $\mathrm{I}$ & - & - & $\begin{array}{l}\text { Buspirone, bupropion, non-benzo- } \\
\text { diazepine, hypnotics, lamotrigine, } \\
\text { gabapentin, clonidine, trazodone } \\
\text { (adjunct), atypical antipsychotics } \\
\text { (mono), atypical antipsychotics } \\
\text { (besides risperidone, adjunct), } \\
\text { conventional antipsychotics, } \\
\text { Propranolol }\end{array}$ & - \\
\hline
\end{tabular}

tricyclic antidepressants (TCAs), such as imipramine and amitriptyline, and the monoamine oxidase inhibitors (MAOIs), such as phenelzine-medications that are effective but have a less favorable side effect profile than SSRI or SNRI medications. The second-line agents also include antidepressants with weaker evidence of effectiveness, such as mirtazapine, or medications effective for PTSD but associated with rare but potentially dangerous side effects, such as nefazodone because of its hepatotoxicity.

The main reason the TCAs and MAOIs are no longer used for depression and anxiety disorders is their low therapeutic index. The difference between their therapeutic and toxic dosages is relatively small. As a general rule, TCA overdose can be lethal when the ingested dose exceeds $2-3 \mathrm{~g}$, and this amount roughly corresponds to a 30-day supply of the TCA at a dose of 75-100 mg daily. Interestingly, there is evidence of cardiac conduction prolongation with citalopram, a drug in the SSRI family, above dosages of $40 \mathrm{mg}$ daily or in overdose [52-53]. Early studies showed both the TCAs and MAOIs to be effective in PTSD, though the outcome measures in those early studies had less sensitivity and specificity than outcome measures in more recent studies [54-55]. Adding to the complexity with MAOIs are the relatively high rates of hypotension and the stringent restrictions for a tyramine-free diet to prevent hypertensive crisis. Potential interactions with other prescriptions must be observed with MAOI use as well.

Mirtazapine acts through the serotonin system and can be a useful alternative to the SSRIs and venlafaxine. Mirtazapine's primary side effect, sedation, can be therapeutically useful for some patients [56]. At higher dosages, it adds noradrenergic stimulation and demonstrates more activating effects. Its sexual side effects are often lower than the SSRIs as well, making it an attractive alternative for patients who report this problem. Weight gain can be a potential problem and must be considered especially in diabetic patients or those at risk for metabolic syndrome.

Nefazodone acts to block reuptake of serotonin as well as postsynaptic receptors. It has been helpful in PTSD and can also target hyperarousal symptoms, such 
as sleep disturbance and anxiety [57]. It carries a black box warning for liver failure, which has occurred in about 1:300,000 cases. It is important to monitor liver functions and to consider nefazodone's use with caution when the patient uses other medications or substances that may irritate the liver, such as statins, divalproex, or large quantities of alcohol. Nefazodone is a potent inhibitor of cytochrome P450-3A4 and will raise blood levels of atorvastatin and other statin drugs, increasing the risk of rhabdomyolysis; patients receiving atorvastatin must be switched to a statin with fewer potential interactions before receiving nefazodone. Nefazodone also raises the blood levels of concurrently taken benzodiazepines because of the cytochrome P450-3A4 inhibition.

Some medications should be avoided in PTSD care. These medications include benzodiazepines and atypical antipsychotics given as monotherapy. Benzodiazepines were not shown to effectively reduce core PTSD symptoms in one trial or to prevent PTSD in another small open trial [13-14]. They are contraindicated for patients with disinhibition and addiction problems. Daily use of benzodiazepines has been shown to interfere with the extinction of fear in prolonged exposure (PE) therapy [58]. Furthermore, additional preliminary evidence from animal studies suggests that benzodiazepines may interfere with PE therapy because they suppress fear extinction [59]. The following case vignette (from Dr. Capehart's practice) illustrates this point:

The veteran was diagnosed with PTSD and panic disorder by a psychiatrist in the PTSD Clinic. He was started on sertraline and after several months at a dose of $200 \mathrm{mg}$ daily, he reported only modest reductions in PTSD symptoms. The panic disorder improved but he continued to take clonazepam $1 \mathrm{mg}$ 1-3 times per week to prevent panic attacks when leaving his home. He was referred for PE therapy. Although the PE went well in the initial weeks, both the patient and his therapist noted that he was relatively unaffected by anxiety in some therapy sessions. A careful review of his medication use found he was taking clonazepam prior to driving from his home to the VA medical center because driving alone was a common trigger for panic attacks. He was encouraged to not use clonazepam within 24 hours of a PE session, and after several more weeks, he completed PE without difficulty. The
post-PE score on the PCL was below the cutoff for PTSD diagnosis.

It is generally known that neither conventional nor atypical antipsychotics are recommended as monotherapy for PTSD. Previously, a number of small single-site studies suggested that atypical antipsychotic agents were effective adjunctive treatment for PTSD patients who had poor responses to first-line SSRIs or SNRIs [60-64]. A recent large-scale multisite trial of risperidone as an adjunctive agent for poor or partial responders to SSRI/ SNRI antidepressants showed no benefit (in comparison with a placebo group) [18]. As a result of this trial, the recently revised CPG will now recommend against the use of risperidone, and evidence is insufficient to recommend any other atypical antipsychotic as adjunctive therapy for PTSD. Atypical antipsychotics have clinically important side effects such as potential elevations in weight, triglycerides, blood pressure, and fasting blood glucose levels [65], factors that must be considered in the risk-benefit analysis before their use.

\section{Effect of Co-Occurring Disorders on Pharmacotherapy}

PTSD and trauma-related distress rarely occur in isolation. They are often accompanied by major depressive disorder (MDD), substance use disorders (SUDs), TBI, and BP. Symptoms from each of these conditions may overlap and require nuanced pharmacotherapy for effective treatment.

The affective disorders commonly co-occur with PTSD [66]. The symptoms of both PTSD and MDD, including sleep disturbance, social withdrawal, and irritability, may overlap. Fortunately, both PTSD and MDD may respond to SSRIs or to venlafaxine, though PTSD with comorbid psychotic depression may be particularly difficult to treat [67]. Pushing antidepressant dosages to the maximal recommended and tolerable dosages is often needed.

Anxiety disorders such as PTSD are often comorbid with SUDs such as alcohol dependence [68]. Patients with a SUD require concurrent care for both the SUD and the PTSD. Evidence exists that this is the most effective course of treatment [69]. Patients must first be observed for acute withdrawal and treated pharmacologically as indicated for any observed withdrawal symptoms. Note that PTSD symptoms may also be exacerbated during the acute withdrawal period, particularly from the increased adrenergic activity associated with alcohol withdrawal. Longer term pharmacotherapy to prevent relapse may 
include naltrexone or disulfiram, which can be used concurrently with recommended PTSD pharmacotherapy. For milder symptoms of trauma-related distress, deferring PTSD pharmacotherapy until after a period of a few weeks' abstinence may be advisable. Evidence exists that sertraline may be helpful in a subgroup of patients for both PTSD and alcohol dependence but not in others [7072]. Patients with a co-occurring SUD are the group at greatest risk for abuse and addiction during long-term benzodiazepine treatment. As with other comorbidities, veterans with co-occurring PTSD and SUD should be treated according to the VA/DOD CPGs for both disorders. Consultation with a SUD specialist clinician often is helpful in providing coordinated interdisciplinary care for the patient with both PTSD and SUD, including nicotine dependence.

The principal of starting low and going slow with medications is true in TBI whether or not it is comorbid with PTSD. The ability to tolerate medications will depend on the extent of the brain injury, its severity, current cognitive impairments, and other factors. There is a lack of well-controlled studies for pharmacologic treatment of the deficits in TBI, with the exception of a few good RCTs for methylphenidate [73-74]. The outcome of these trials demonstrated improvements in executive functioning and other cognitive functions, such as attention and memory. Most of the TBIs in veterans returning from Iraq and Afghanistan are mild in nature, and many of the treatment studies for TBI-related cognitive problems occurred in persons with moderate to severe TBI. Thus, assuming that a treatment trial showing cognitive improvement in moderate to severe TBI will cause similar improvement in a veteran with mild TBI is somewhat problematic. If a stimulant such as methylphenidate is considered for cognitive problems after TBI, it is highly recommended that the planned prescription be discussed with the veteran's psychiatrist or that a referral for psychiatric evaluation be made. Stimulant medication carries a known risk for worsening anxiety symptoms, and reasonable concern exists that the stimulant may simultaneously improve the TBI-related cognitive problem but greatly aggravate the anxiety symptoms of PTSD. It is recommended that trauma-focused psychotherapy be considered for patients with co-occurring PTSD and mild TBI [75]. Furthermore, no clear evidence exists that standard pharmacotherapy for PTSD is contraindicated in patients with comorbid TBI [76]. We recommend optimizing PTSD care with both medication and psychother- apy before considering any medication for improving TBI-related cognitive deficits. Additional useful considerations include reducing comorbid pain, treating any sleep disorder that may be present, and treating any comorbid SUD. These additional steps should also improve any cognitive deficits and may remove the need to start a stimulant that could greatly aggravate PTSD symptoms. Mental health consultation early in the course of treatment is important for management of these cooccurring disorders, and the optimal treatment approach will utilize an interdisciplinary team, including the mental health and the clinical team providing TBI care.

$\mathrm{BP}$ is a very difficult condition to treat alone and is especially complicated when comorbid with PTSD [77]. Mood stabilizers such as lithium and valproate are the primary medications for treatment of BP. However, large multisite RCTs found that valproate, topiramate, and tiagabine did not improve PTSD symptoms [78-80] and the evidence supporting lamotrigene for PTSD is poor [81]. Atypical antipsychotics are useful for the acute treatment of mania or psychosis but have limited evidence supporting their use in PTSD as described previously. Psychotherapy for the PTSD diagnosis would be especially important to consider in these cases. If an SSRI or venlafaxine is started, we would recommend beginning at a low dosage and increasing slowly, observing for hypomania or mania.

\section{Next Steps in Treatment}

The first step is to assess the effect of the intervention on PTSD symptoms with a measure such as the PCL. If the patient is not responding, then it is important to look at adherence and dosage. Adherence to medication regimens for depression and anxiety disorders is often below 50 percent in outpatients [82]. If the patient is being treated on an inpatient medical or general psychiatry unit, the problem of adherence is easier to manage. If the patient is not adherent to medication, it is important to determine the reasons for that nonadherence, such as medication side effects and treatment preferences [8384]. If the patient is adherent, then the patient should complete a trial of 8 to 12 weeks for an SSRI or venlafaxine at maximally tolerated dosages within the recommended treatment range before considering adjunctive treatments or other therapeutic approaches.

If the patient has received adequate dosages of the agent and an adequate duration of treatment, then it is reasonable to switch to another agent within the SSRI 
group, add psychotherapy, or address specific symptoms such as sleep disturbance with agents such as prazosin for nightmares or sedating antidepressants such as trazodone or mirtazapine. Medical management of severe anger outbursts is difficult. Studies treating PTSD-related anger with mood stabilizers such as divalproex or the atypical antipsychotic risperidone have failed to show efficacy $[18,78]$. Psychotherapy, behavioral interventions, and use of different first-line agents are the best approach supported by the available evidence and are recommended in the 2010 revision to the CPG.

Second-line agents can be considered as the next treatment step if these first-line agents are not effective in treatment (Figure). We recommend doing this in consultation with a specialist in pharmacotherapy in psychiatric disorders, given the potential side effects from these medications.

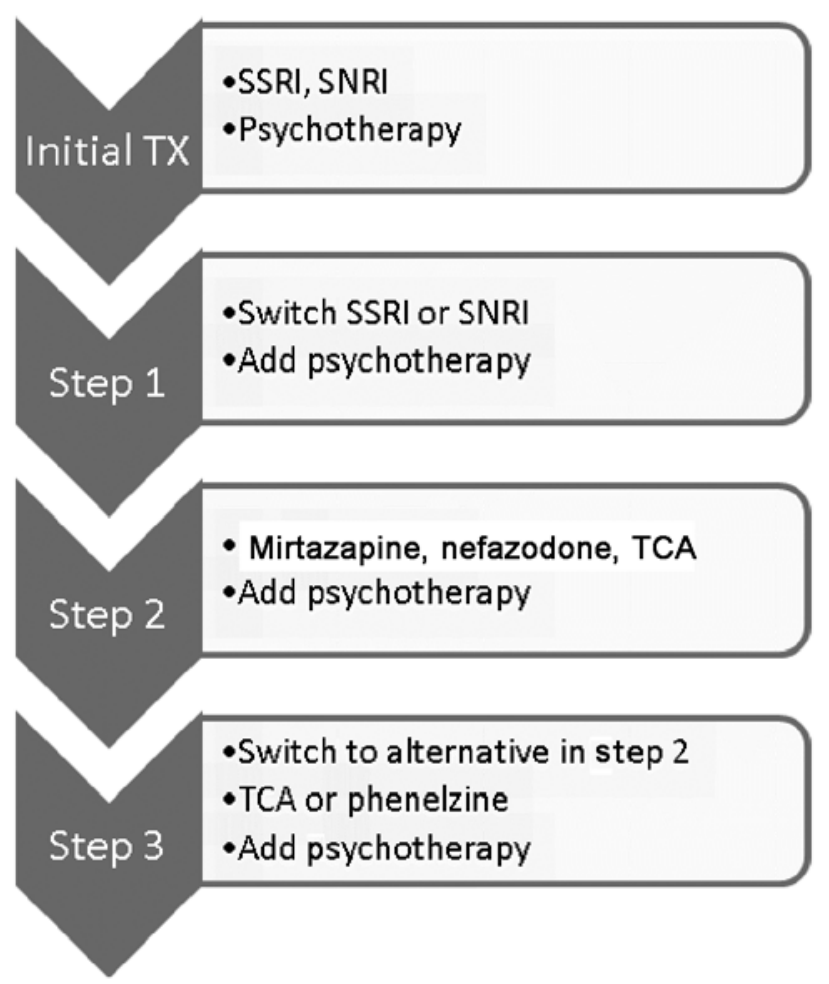

Figure.

Stepped care for pharmacotherapy in posttraumatic stress disorder (PTSD). Adapted from Department of Veterans Affairs/Department of Defense Clinical Practice Guideline for Management of Post-Traumatic Stress. SNRI = serotonin-norepinephrine reuptake inhibitor, SSRI = selective serotonin reuptake inhibitor, $\mathrm{TCA}=$ tricyclic antidepressant, $\mathrm{TX}=$ treatment.

\section{DISCUSSION}

Trauma-focused psychotherapy is the recommended first-line treatment for PTSD [85], but pharmacotherapy plays an important role for patients as an intervention because of patient preference and/or limited availability of psychotherapy. Medications can play an important role for PTSD symptom reduction, which can improve the engagement of patients in their treatment.

Given the medication choices available, it is important to begin with agents as recommended in the CPG. In our collective experience, the SSRIs and venlafaxine carry the strongest evidence of effectiveness and safety and most patients will have at least a partial response to these medications. These medications potentially are of most benefit to the patient and provide a solid treatment foundation for further mental health care, ideally one of the trauma-focused psychotherapies. Given the modest long-term results from pharmacotherapy, an entirely reasonable treatment strategy is referral to trauma-focused psychotherapy after the medication response reaches a plateau. Ongoing medication changes are unlikely to bring about the same degree of improvement as traumafocused psychotherapy, and referral to such therapy is often indicated for the patient's recovery.

For patients who cannot tolerate the first-line medications, mirtazapine is a reasonable second-line medication, although evidence for its effectiveness is not as strong as for first-line agents. Nefazodone is effective for PTSD but is associated with rare but serious hepatotoxicity. TCAs may be used but have significant side effects and carry the risk of toxicity if taken in an overdose. MAOIs would best be used under the supervision of a prescribing psychiatrist experienced with their use. Certain agents, such as atypical antipsychotics like monotherapy and benzodiazepines, should be avoided. Furthermore, initiating benzodiazepines may interfere with psychotherapy initiated later in treatment, as illustrated in the earlier case vignette.

Recognizing and treating comorbid conditions are also key to successful pharmacotherapy. Making the right choice of medication depends on the patient's unique situation and preferences. For example, a patient might accept some sexual dysfunction on an SSRI if the SSRI reduces traumatic nightmares or irritability. In all cases, the patient preferences, comorbid medical and psychiatric conditions, evidence for treatment, and outcomes should all be considered while minimizing side effects. Consultation with mental health is an important step following 
an assessment of the response to initial pharmacotherapy within the primary or specialty medical care setting.

\section{CONCLUSIONS}

Providing evidenced-based pharmacotherapy for nightmares, anxiety, irritability, and other PTSD symptoms in an empathic setting that encourages engagement in treatment can be of great benefit to patients and the treatment team and can improve treatment outcomes. Following the CPG will help bridge the gap between primary care providers, nonpsychiatric specialist physicians, and mental health care, leading to a more engaged and less anxious patient.

Several important practices can maximize treatment effectiveness for patients with PTSD and trauma-related distress in the clinical setting. Effective screening for PTSD and trauma-related distress is important initially to improve patient and staff understanding of the emotional factors affecting recovery. The PCL can be effectively used to monitor trauma-related distress and is quite easy to administer either as a manual paper copy or within the VA electronic medical record.

The CPG provides a solid foundation for pharmacotherapy preceding more complex and nuanced treatment by mental health professionals in the future. It provides effective recommendations for first-line pharmacotherapy and psychotherapy options for patients. First- and second-line pharmacotherapy must be distinguished and discussed with patients in the context of a strong treatment alliance.

\section{ACKNOWLEDGMENTS}

\author{
Author Contributions: \\ Analysis and interpretation of data: M. Jeffreys, B. Capehart, \\ M. J. Friedman. \\ Drafting of manuscript: M. Jeffreys, B. Capehart, M. J. Friedman. \\ Critical revision of manuscript for important intellectual content: \\ M. Jeffreys, B. Capehart, M. J. Friedman. \\ Administrative, technical, or material support: M. J. Friedman.
}

Financial Disclosures: The authors have declared that no competing interests exist.

Funding/Support: This material was unfunded at the time of manuscript preparation.

\section{REFERENCES}

1. Kessler RC, Sonnega A, Bromet E, Hughes M, Nelson CB. Posttraumatic stress disorder in the National Comorbidity Survey. Arch Gen Psychiatry. 1995;52(12):1048-60. [PMID:7492257] http://dx.doi.org/10.1001/archpsyc.1995.03950240066012

2. Dohrenwend BP, Turner JB, Turse NA, Adams BG, Koenen KC, Marshall R. Continuing controversy over the psychological risks of Vietnam for U.S. veterans. J Trauma Stress. 2007;20(4):449-65. [PMID:17721952] http://dx.doi.org/10.1002/jts.20296

3. Hoge CW, Terhakopian A, Castro CA, Messer SC, Engel CC. Association of posttraumatic stress disorder with somatic symptoms, health care visits, and absenteeism among Iraq war veterans. Am J Psychiatry. 2007;164(1): 150-53. [PMID:17202557] http://dx.doi.org/10.1176/appi.ajp.164.1.150

4. Spiro A 3rd, Hankin CS, Mansell D, Kazis LE. Posttraumatic stress disorder and health status: the veterans health study. J Ambul Care Manage. 2006;29(1):71-86. [PMID:16340621]

5. Magruder KM, Frueh BC, Knapp RG, Davis L, Hamner MB, Martin RH, Gold PB, Arana GW. Prevalence of posttraumatic stress disorder in Veterans Affairs primary care clinics. Gen Hosp Psychiatry. 2005;27(3):169-79.

[PMID:15882763]

http://dx.doi.org/10.1016/j.genhosppsych.2004.11.001

6. Lecrubier Y. Posttraumatic stress disorder in primary care: a hidden diagnosis. J Clin Psychiatry. 2004;65(Suppl 1): 49-54. [PMID:14728097]

7. Richardson JD, Elhai JD, Pedlar DJ. Association of PTSD and depression with medical and specialist care utilization in modern peacekeeping veterans in Canada with healthrelated disabilities. J Clin Psychiatry. 2006;67(8):1240-45. [PMID:16965202] http://dx.doi.org/10.4088/JCP.v67n0810

8. Hankin CS, Spiro A 3rd, Miller DR, Kazis L. Mental disorders and mental health treatment among U.S. Department of Veterans Affairs outpatients: the Veterans Health Study. Am J Psychiatry. 1999;156(12):1924-30. [PMID:10588406]

9. Dobie DJ, Kivlahan DR, Maynard C, Bush KR, McFall M, Epler AJ, Bradley KA. Screening for post-traumatic stress disorder in female Veteran's Affairs patients: validation of the PTSD checklist. Gen Hosp Psychiatry. 2002;24(6):367-74. [PMID:12490337] http://dx.doi.org/10.1016/S0163-8343(02)00207-4

10. Bullman TA, Kang HK, Thomas TL. Posttraumatic stress disorder among Vietnam veterans on the Agent Orange Registry. A case-control analysis. Ann Epidemiol. 1991; 
1(6):505-12. [PMID:1669530]

http://dx.doi.org/10.1016/1047-2797(91)90022-5

11. Hermos JA, Young MM, Lawler EV, Stedman MR, Gagnon DR, Fiore LD. Characterizations of long-term anxiolytic benzodiazepine prescriptions in veteran patients. J Clin Psychopharmacol. 2005;25(6):600-604. [PMID:16282847] http://dx.doi.org/10.1097/01.jcp.0000185430.10053.1e

12. Hermos JA, Young MM, Lawler EV, Rosenbloom D, Fiore LD. Long-term, high-dose benzodiazepine prescriptions in veteran patients with PTSD: influence of preexisting alcoholism and drug-abuse diagnoses. J Trauma Stress. 2007; 20(5):909-14. [PMID:17955537]

http://dx.doi.org/10.1002/jts.20254

13. Braun P, Greenberg D, Dasberg H, Lerer B. Core symptoms of posttraumatic stress disorder unimproved by alprazolam treatment. J Clin Psychiatry. 1990;51(6):236-38. [PMID:2189869]

14. Gelpin E, Bonne O, Peri T, Brandes D, Shalev AY. Treatment of recent trauma survivors with benzodiazepines: a prospective study. J Clin Psychiatry. 1996;57(9):390-94. [PMID:9746445]

15. Leslie DL, Mohamed S, Rosenheck RA. Off-label use of antipsychotic medications in the department of Veterans Affairs health care system. Psychiatr Serv. 2009;60(9): 1175-81. [PMID:19723731]

http://dx.doi.org/10.1176/appi.ps.60.9.1175

16. Mohamed S, Rosenheck RA. Pharmacotherapy of PTSD in the U.S. Department of Veterans Affairs: diagnostic- and symptom-guided drug selection. J Clin Psychiatry. 2008; 69(6):959-65. [PMID:18588361] http://dx.doi.org/10.4088/JCP.v69n0611

17. The Management of Post-Traumatic Stress Working Group [Internet]. VA/DOD clinical practice guideline for management of post-traumatic stress. Washington (DC): Office of Quality and Performance, Department of Veterans Affairs; 2010. Available from: http://www.healthquality.va.gov/ ptsd.ptsd_full.pdf

18. Krystal JH, Rosenheck RA, Cramer JA, Vessicchio JC, Jones KM, Vertrees JE, Horney RA, Huang GD, Stock C; Veterans Affairs Cooperative Study No. 504 Group. Adjunctive risperidone treatment for antidepressant-resistant symptoms of chronic military service-related PTSD: a randomized trial. JAMA. 2011;306(5):493-502.

[PMID:21813427]

http://dx.doi.org/10.1001/jama.2011.1080

19. Seal KH, Maguen S, Cohen B, Gima KS, Metzler TJ, Ren L, Bertenthal D, Marmar CR. VA mental health services utilization in Iraq and Afghanistan veterans in the first year of receiving new mental health diagnoses. J Trauma Stress. 2010;23(1):5-16. [PMID:20146392]
20. Weathers FW, Huska JA, Keane TM. PCL-M for DSM-IV. Boston (MA): National Center for PTSD—Behavioral Science Division; 1991.

21. American Psychiatric Association. Diagnostic and statistical manual of mental disorders, 4th edition. Washington (DC): American Psychiatric Association; 1994.

22. Brewin CR, Andrews B, Valentine JD. Meta-analysis of risk factors for posttraumatic stress disorder in trauma-exposed adults. J Consult Clin Psychol. 2000;68(5):748-66.

[PMID:11068961]

http://dx.doi.org/10.1037/0022-006X.68.5.748

23. Brewin CR, Holmes EA. Psychological theories of posttraumatic stress disorder. Clin Psychol Rev. 2003;23(3): 339-76. [PMID:12729677] http://dx.doi.org/10.1016/S0272-7358(03)00033-3

24. Ozer EJ, Best SR, Lipsey TL, Weiss DS. Predictors of posttraumatic stress disorder and symptoms in adults: a metaanalysis. Psychol Bull. 2003;129(1):52-73.

[PMID:12555794] http://dx.doi.org/10.1037/0033-2909.129.1.52

25. Keane TM, Marshall AD, Taft CT. Posttraumatic stress disorder: etiology, epidemiology, and treatment outcome. Annu Rev Clin Psychol. 2006;2:161-97. [PMID:17716068] http://dx.doi.org/10.1146/annurev.clinpsy.2.022305.095305

26. Seal KH, Bertenthal D, Miner CR, Sen S, Marmar C. Bringing the war back home: mental health disorders among 103,788 US veterans returning from Iraq and Afghanistan seen at Department of Veterans Affairs facilities. Arch Intern Med. 2007;167(5):476-82. [PMID:17353495] http://dx.doi.org/10.1001/archinte.167.5.476

27. Hoge CW, McGurk D, Thomas JL, Cox AL, Engel CC, Castro CA. Mild traumatic brain injury in U.S. soldiers returning from Iraq. N Engl J Med. 2008;358(5):453-63. [PMID:18234750] http://dx.doi.org/10.1056/NEJMoa072972

28. Sayer NA, Friedemann-Sanchez G, Spoont M, Murdoch M, Parker LE, Chiros C, Rosenheck R. A qualitative study of determinants of PTSD treatment initiation in veterans. Psychiatry. 2009;72(3):238-55. [PMID:19821647] http://dx.doi.org/10.1521/psyc.2009.72.3.238

29. Jeffreys MD, Leibowitz RQ, Finley E, Arar N. Trauma disclosure to health care professionals by veterans: clinical implications. Mil Med. 2010;175(10):719-24. [PMID:20968260]

30. Weathers FW, Keane TM, Davidson JR. Clinician-administered PTSD scale: a review of the first ten years of research. Depress Anxiety. 2001;13(3):132-56. [PMID:11387733] http://dx.doi.org/10.1002/da.1029

31. McDonald SD, Calhoun PS. The diagnostic accuracy of the PTSD checklist: a critical review. Clin Psychol Rev. 2010; 30(8):976-87. [PMID:20705376] http://dx.doi.org/10.1016/j.cpr.2010.06.012 
32. Grubaugh AL, Elhai JD, Cusack KJ, Wells C, Frueh BC. Screening for PTSD in public-sector mental health settings: the diagnostic utility of the PTSD checklist. Depress Anxiety. 2007;24(2):124-29. [PMID:16892418] http://dx.doi.org/10.1002/da.20226

33. Yeager DE, Magruder KM, Knapp RG, Nicholas JS, Frueh BC. Performance characteristics of the posttraumatic stress disorder checklist and SPAN in Veterans Affairs primary care settings. Gen Hosp Psychiatry. 2007;29(4):294-301. [PMID:17591505] http://dx.doi.org/10.1016/j.genhosppsych.2007.03.004

34. Shin LM, Handwerger K. Is posttraumatic stress disorder a stress-induced fear circuitry disorder? J Trauma Stress. 2009;22(5):409-15. [PMID:19743481]

http://dx.doi.org/10.1002/jts.20442

35. Murrough JW, Huang Y, Hu J, Henry S, Williams W, Gallezot JD, Bailey CR, Krystal JH, Carson RE, Neumeister A. Reduced amygdala serotonin transporter binding in posttraumatic stress disorder. Biol Psychiatry. 2011;70(11): 1033-38. [PMID:21855859] http://dx.doi.org/10.1016/j.biopsych.2011.07.003

36. Wessa M, Rohleder N, Kirschbaum C, Flor H. Altered cortisol awakening response in posttraumatic stress disorder. Psychoneuroendocrinology. 2006;31(2):209-15. [PMID:16154709] http://dx.doi.org/10.1016/j.psyneuen.2005.06.010

37. Yehuda R. Biology of posttraumatic stress disorder. J Clin Psychiatry. 2001;62(Suppl 17):41-46. [PMID:11495096]

38. De Kloet CS, Vermetten E, Geuze E, Kavelaars A, Heijnen CJ, Westenberg HG. Assessment of HPA-axis function in posttraumatic stress disorder: pharmacological and nonpharmacological challenge tests, a review. J Psychiatr Res. 2006;40(6):550-67. [PMID:16214171]

http://dx.doi.org/10.1016/j.jpsychires.2005.08.002

39. Pole N. The psychophysiology of posttraumatic stress disorder: a meta-analysis. Psychol Bull. 2007;133(5):725-46. [PMID:17723027] http://dx.doi.org/10.1037/0033-2909.133.5.725

40. Marshall RD, Lewis-Fernandez R, Blanco C, Simpson HB, Lin SH, Vermes D, Garcia W, Schneier F, Neria Y, Sanchez-Lacay A, Liebowitz MR. A controlled trial of paroxetine for chronic PTSD, dissociation, and interpersonal problems in mostly minority adults. Depress Anxiety. 2007;24(2):77-84. [PMID:16892419]

http://dx.doi.org/10.1002/da.20176

41. Brady K, Pearlstein T, Asnis GM, Baker D, Rothbaum B, Sikes CR, Farfel GM. Efficacy and safety of sertraline treatment of posttraumatic stress disorder: a randomized controlled trial. JAMA. 2000;283(14):1837-44.

[PMID:10770145]

http://dx.doi.org/10.1001/jama.283.14.1837

42. Davidson J, Baldwin D, Stein DJ, Kuper E, Benattia I, Ahmed S, Pedersen R, Musgnung J. Treatment of posttraumatic stress disorder with venlafaxine extended release: a 6-month randomized controlled trial. Arch Gen Psychiatry. 2006;63(10):1158-65. [PMID:17015818]

http://dx.doi.org/10.1001/archpsyc.63.10.1158

43. Davidson J, Pearlstein T, Londborg P, Brady KT, Rothbaum B, Bell J, Maddock R, Hegel MT, Farfel G. Efficacy of sertraline in preventing relapse of posttraumatic stress disorder: results of a 28-week double-blind, placebo-controlled study. Am J Psychiatry. 2001;158(12):1974-81. [PMID:11729012] http://dx.doi.org/10.1176/appi.ajp.158.12.1974

44. Davidson JR, Connor KM, Hertzberg MA, Weisler RH, Wilson WH, Payne VM. Maintenance therapy with fluoxetine in posttraumatic stress disorder: a placebo-controlled discontinuation study. J Clin Psychopharmacol. 2005; 25(2):166-69. [PMID:15738748] http://dx.doi.org/10.1097/01.jcp.0000155817.21467.6c

45. Martenyi F, Soldatenkova V. Fluoxetine in the acute treatment and relapse prevention of combat-related post-traumatic stress disorder: Analysis of the veteran group of a placebo-controlled, randomized clinical trial. Eur Neuropsychopharmacol. 2006;16(5):340-49. [PMID:16356696] http://dx.doi.org/10.1016/j.euroneuro.2005.10.007

46. Seedat S, Stein DJ, Emsley RA. Open trial of citalopram in adults with post-traumatic stress disorder. Int J Neuropsychopharmacol. 2000;3(2):135-40. [PMID:11343590] http://dx.doi.org/10.1017/S1461145700001899

47. Escalona R, Canive JM, Calais LA, Davidson JR. Fluvoxamine treatment in veterans with combat-related post-traumatic stress disorder. Depress Anxiety. 2002;15(1):29-33. [PMID:11816050] http://dx.doi.org/10.1002/da.1082

48. Friedman MJ, Marmar CR, Baker DG, Sikes CR, Farfel GM. Randomized, double-blind comparison of sertraline and placebo for posttraumatic stress disorder in a Department of Veterans Affairs setting. J Clin Psychiatry. 2007; 68(5):711-20. [PMID:17503980]

http://dx.doi.org/10.4088/JCP.v68n0508

49. Calohan J, Peterson K, Peskind ER, Raskind MA. Prazosin treatment of trauma nightmares and sleep disturbance in soldiers deployed in Iraq. J Trauma Stress. 2010;23(5): 645-48. [PMID:20931662] http://dx.doi.org/10.1002/jts.20570

50. Taylor FB, Martin P, Thompson C, Williams J, Mellman TA, Gross C, Peskind ER, Raskind MA. Prazosin effects on objective sleep measures and clinical symptoms in civilian trauma posttraumatic stress disorder: a placebo-controlled study. Biol Psychiatry. 2008;63(6):629-32.

[PMID:17868655]

http://dx.doi.org/10.1016/j.biopsych.2007.07.001

51. Raskind MA, Peskind ER, Hoff DJ, Hart KL, Holmes HA, Warren D, Shofer J, O’Connell J, Taylor F, Gross C, Rohde $\mathrm{K}$, McFall ME. A parallel group placebo controlled study of prazosin for trauma nightmares and sleep disturbance in 
combat veterans with post-traumatic stress disorder. Biol Psychiatry. 2007;61(8):928-34. [PMID:17069768]

http://dx.doi.org/10.1016/j.biopsych.2006.06.032

52. Kelly CA, Dhaun N, Laing WJ, Strachan FE, Good AM, Bateman DN. Comparative toxicity of citalopram and the newer antidepressants after overdose. J Toxicol Clin Toxicol. 2004;42(1):67-71. [PMID:15083939]

http://dx.doi.org/10.1081/CLT-120028747

53. U.S. Food and Drug Administration. FDA drug safety communication: Abnormal heart rhythms associated with high doses of Celexa (citalopram hydrobromide) [Internet]. Silver Spring (MD): U.S. Food and Drug Administration; 2011 Aug 24 [updated 2012 Mar 28]. Available from: http://www.fda.gov/Drugs/DrugSafety/ucm269086.htm

54. Kosten TR, Frank JB, Dan E, McDougle CJ, Giller EL Jr. Pharmacotherapy for posttraumatic stress disorder using phenelzine or imipramine. J Nerv Ment Dis. 1991;179(6): 366-70. [PMID:2051152] http://dx.doi.org/10.1097/00005053-199106000-00011

55. Frank JB, Kosten TR, Giller EL Jr, Dan E. A randomized clinical trial of phenelzine and imipramine for posttraumatic stress disorder. Am J Psychiatry. 1988;145(10): 1289-91. [PMID:3048121]

56. Chung MY, Min KH, Jun YJ, Kim SS, Kim WC, Jun EM. Efficacy and tolerability of mirtazapine and sertraline in Korean veterans with posttraumatic stress disorder: a randomized open label trial. Hum Psychopharmacol. 2004; 19(7):489-94. [PMID:15378676] http://dx.doi.org/10.1002/hup.615

57. Davis LL, Jewell ME, Ambrose S, Farley J, English B, Bartolucci A, Petty F. A placebo-controlled study of nefazodone for the treatment of chronic posttraumatic stress disorder: a preliminary study. J Clin Psychopharmacol. 2004; 24(3):291-97. [PMID:15118483] http://dx.doi.org/10.1097/01.jcp.0000125685.82219.1a

58. Van Minnen A, Arntz A, Keijsers GP. Prolonged exposure in patients with chronic PTSD: predictors of treatment outcome and dropout. Behav Res Ther. 2002;40(4):439-57. [PMID:12002900] http://dx.doi.org/10.1016/S0005-7967(01)00024-9

59. Birk L. Pharmacotherapy for performance anxiety disorders: occasionally useful but typically contraindicated. J Clin Psychol. 2004;60(8):867-79. [PMID:15241814] http://dx.doi.org/10.1002/jclp.20044

60. Hamner MB, Faldowski RA, Ulmer HG, Frueh BC, Huber MG, Arana GW. Adjunctive risperidone treatment in posttraumatic stress disorder: a preliminary controlled trial of effects on comorbid psychotic symptoms. Int Clin Psychopharmacol. 2003;18(1):1-8. [PMID:12490768] http://dx.doi.org/10.1097/00004850-200301000-00001

61. Monnelly EP, Ciraulo DA, Knapp C, Keane T. Low-dose risperidone as adjunctive therapy for irritable aggression in posttraumatic stress disorder. J Clin Psychopharmacol. 2003;23(2):193-96. [PMID:12640221]

http://dx.doi.org/10.1097/00004714-200304000-00012

62. Reich DB, Winternitz S, Hennen J, Watts T, Stanculescu C. A preliminary study of risperidone in the treatment of posttraumatic stress disorder related to childhood abuse in women. J Clin Psychiatry. 2004;65(12):1601-6.

[PMID:15641864]

http://dx.doi.org/10.4088/JCP.v65n1204

63. Bartzokis G, Lu PH, Turner J, Mintz J, Saunders CS. Adjunctive risperidone in the treatment of chronic combatrelated posttraumatic stress disorder. Biol Psychiatry. 2005; 57(5):474-79. [PMID:15737661] http://dx.doi.org/10.1016/j.biopsych.2004.11.039

64. Rothbaum BO, Killeen TK, Davidson JR, Brady KT, Connor KM, Heekin MH. Placebo-controlled trial of risperidone augmentation for selective serotonin reuptake inhibitor-resistant civilian posttraumatic stress disorder. J Clin Psychiatry. 2008;69(4):520-25. [PMID:18278987] http://dx.doi.org/10.4088/JCP.v69n0402

65. Meyer JM. Antipsychotic safety and efficacy concerns. J Clin Psychiatry. 2007;68(Suppl 14):20-26. [PMID:18284274]

66. Campbell DG, Felker BL, Liu CF, Yano EM, Kirchner JE, Chan D, Rubenstein LV, Chaney EF. Prevalence of depression-PTSD comorbidity: implications for clinical practice guidelines and primary care-based interventions. J Gen Intern Med. 2007;22(6):711-18. [PMID:17503104] http://dx.doi.org/10.1007/s11606-006-0101-4

67. Gaudiano BA, Zimmerman M. Does comorbid posttraumatic stress disorder affect the severity and course of psychotic major depressive disorder? J Clin Psychiatry. 2010; 71(4):442-50. [PMID:20021993] http://dx.doi.org/10.4088/JCP.08m04794gre

68. Marquenie LA, Schadé A, van Balkom AJ, Comijs HC, de Graaf R, Vollebergh W, van Dyck R, van den Brink W. Origin of the comorbidity of anxiety disorders and alcohol dependence: findings of a general population study. Eur Addict Res. 2007;13(1):39-49. [PMID:17172778] http://dx.doi.org/10.1159/000095814

69. Hien DA, Jiang H, Campbell AN, Hu MC, Miele GM, Cohen LR, Brigham GS, Capstick C, Kulaga A, Robinson J, Suarez-Morales L, Nunes EV. Do treatment improvements in PTSD severity affect substance use outcomes? A secondary analysis from a randomized clinical trial in NIDA’s Clinical Trials Network. Am J Psychiatry. 2010; 167(1):95-101. [PMID:19917596] http://dx.doi.org/10.1176/appi.ajp.2009.09091261

70. Brady KT. Evidence-based pharmacotherapy for mood and anxiety disorders with concurrent alcoholism. CNS Spectr. 2008;13(4, Suppl 6):7-9. [PMID:19317017]

71. Brady KT, Sonne S, Anton RF, Randall CL, Back SE, Simpson K. Sertraline in the treatment of co-occurring alcohol 
dependence and posttraumatic stress disorder. Alcohol Clin Exp Res. 2005;29(3):395-401. [PMID:15770115] http://dx.doi.org/10.1097/01.ALC.0000156129.98265.57

72. Roache JD, Wang Y, Ait-Daoud N, Johnson BA. Prediction of serotonergic treatment efficacy using age of onset and Type A/B typologies of alcoholism. Alcohol Clin Exp Res. 2008;32(8):1502-12. [PMID:18565156] http://dx.doi.org/10.1111/j.1530-0277.2008.00717.x

73. Warden DL, Gordon B, McAllister TW, Silver JM, Barth JT, Bruns J, Drake A, Gentry T, Jagoda A, Katz DI, Kraus J, Labbate LA, Ryan LM, Sparling MB, Walters B, Whyte J, Zapata A, Zitnay G; Neurobehavioral Guidelines Working Group. Guidelines for the pharmacologic treatment of neurobehavioral sequelae of traumatic brain injury. J Neurotrauma. 2006;23(10):1468-1501. [PMID:17020483] http://dx.doi.org/10.1089/neu.2006.23.1468

74. Writer BW, Schillerstrom JE. Psychopharmacological treatment for cognitive impairment in survivors of traumatic brain injury: a critical review. J Neuropsychiatry Clin Neurosci. 2009;21(4):362-70. [PMID:19996244] http://dx.doi.org/10.1176/appi.neuropsych.21.4.362

75. Chard KM, Schumm JA, McIlvain SM, Bailey GW, Parkinson RB. Exploring the efficacy of a residential treatment program incorporating cognitive processing therapy-cognitive for veterans with PTSD and traumatic brain injury. J Trauma Stress. 2011;24(3):347-51. [PMID:21626573] http://dx.doi.org/10.1002/jts.20644

76. Carlson K, Kehle S, Meis L, Greer N, MacDonald R, Rutks I, Wilt TJ. The assessment and treatment of individuals with history of traumatic brain injury and post-traumatic stress disorder: a systematic review of the evidence. Washington (DC): Department of Veterans Affairs; 2009.

77. Otto MW, Perlman CA, Wernicke R, Reese HE, Bauer MS, Pollack MH. Posttraumatic stress disorder in patients with bipolar disorder: a review of prevalence, correlates, and treatment strategies. Bipolar Disord. 2004;6(6):470-79. [PMID:15541062] http://dx.doi.org/10.1111/j.1399-5618.2004.00151.x

78. Davis LL, Davidson JR, Ward LC, Bartolucci A, Bowden CL, Petty F. Divalproex in the treatment of posttraumatic stress disorder: a randomized, double-blind, placebo-controlled trial in a veteran population. J Clin Psychopharmacol. 2008;28(1):84-88. [PMID:18204347] http://dx.doi.org/10.1097/JCP.0b013e318160f83b

79. Tucker P, Trautman RP, Wyatt DB, Thompson J, Wu SC, Capece JA, Rosenthal NR. Efficacy and safety of topiramate monotherapy in civilian posttraumatic stress disorder: a randomized, double-blind, placebo-controlled study.
J Clin Psychiatry. 2007;68(2):201-6. [PMID:17335317] http://dx.doi.org/10.4088/JCP.v68n0204

80. Davidson JR, Brady K, Mellman TA, Stein MB, Pollack $\mathrm{MH}$. The efficacy and tolerability of tiagabine in adult patients with post-traumatic stress disorder. J Clin Psychopharmacol. 2007;27(1):85-88. [PMID:17224720] http://dx.doi.org/10.1097/JCP.0b013e31802e5115

81. Hertzberg MA, Butterfield MI, Feldman ME, Beckham JC, Sutherland SM, Connor KM, Davidson JR. A preliminary study of lamotrigine for the treatment of posttraumatic stress disorder. Biol Psychiatry. 1999;45(9):1226-29.

[PMID:10331117]

http://dx.doi.org/10.1016/S0006-3223(99)00011-6

82. Sheehan DV, Keene MS, Eaddy M, Krulewicz S, Kraus JE, Carpenter DJ. Differences in medication adherence and healthcare resource utilization patterns: older versus newer antidepressant agents in patients with depression and/or anxiety disorders. CNS Drugs. 2008;22(11):963-73.

[PMID:18840035] http://dx.doi.org/10.2165/00023210-200822110-00005

83. Van Schaik DJ, Klijn AF, van Hout HP, van Marwijk HW, Beekman AT, de Haan M, van Dyck R. Patients’ preferences in the treatment of depressive disorder in primary care. Gen Hosp Psychiatry. 2004;26(3):184-89. [PMID:15121346] http://dx.doi.org/10.1016/j.genhosppsych.2003.12.001

84. Vergouwen AC, Bakker A, Katon WJ, Verheij TJ, Koerselman F. Improving adherence to antidepressants: a systematic review of interventions. J Clin Psychiatry. 2003; 64(12):1415-20. [PMID:14728101] http://dx.doi.org/10.4088/JCP.v64n1203

85. Shalev AY. Posttraumatic stress disorder and stress-related disorders. Psychiatr Clin North Am. 2009;32(3):687-704. [PMID:19716997] http://dx.doi.org/10.1016/j.psc.2009.06.001

Submitted for publication September 30, 2011. Accepted in revised form November 8, 2011.

This article and any supplementary material should be cited as follows:

Jeffreys M, Capehart B, Friedman MJ. Pharmacotherapy for posttraumatic stress disorder: Review with clinical applications. J Rehabil Res Dev. 2012;49(5):703-16. http://dx.doi.org/10.1682/JRRD.2011.09.0183

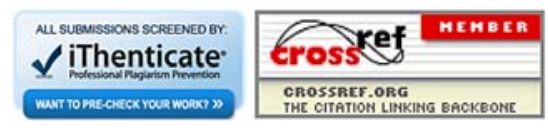


